\title{
Preparing for the CU-TEP Examination: Methods Used by Thai Students
}

\section{JANE M. SCRYMGEOUR \\ Thailand}

\begin{abstract}
Bio Data:
Jane Scrymgeour, from New Zealand, is currently teaching English part-time at private language schools in Bangkok. She has been an ESL teacher for 5 years: Thailand, Cambodia, Cuba, Mexico, Saudi Arabia, and previously a librarian and a primary school teacher in New Zealand.
\end{abstract}

\begin{abstract}
This paper discusses how a group of students from Chulalongkorn University prepared for the CU-Tep examination. In order to gather the information, a questionnaire was given to 16 students from the Education Department of Chulalongkorn University. The findings indicated three things. First, was the general lack of preparation by approximately half of the candidates. Second, was that all of the students found the examination difficult, even those who said they did some preparation. Third, was the relatively poor scores received by Thai students as noted in the research cited. Some recommendations for the students: listen to and follow the advice of those who have previously taken the exam, do lots of preparation by taking practice tests and seek help from others.
\end{abstract}

\section{Introduction}

According to Dr Kanchana Prapphal (2002) the average scores for the TOEFL equivalent of the CU-Tep exam have shown that Thai science students received 450 points, social and humanities 444 points, international programme students 489 . This meant that Thai students have an average below 500, along with Laos, and are therefore rated about eighth when compared with the ten other South East Asian countries. Compared to Singapore and the Philippines who have scored more than 550, and Malaysia, Indonesia, Myanmar, Vietnam and Cambodia who have all 
averaged above 500, Thai students have not being doing very well and certainly not as well as had been expected with regards to learning the English language. Arunee Wiriyachitra in her abstract (2002) noted that the Minister from the Ministry of University Affairs had also said that the average TOEFL scores of Thais were the same as the Mongolians but were higher than North Koreans and Japanese. The Bangkok Post reported in August 2005 that Thailand continued to be ranked very low, remaining at eighth place. Dr Prapphal (2002) also mentioned that the "majority of students could not meet the required standards in order to study at graduate level at Chulalongkorn University." It has also been noted that universities in western countries usually require a score of 550 points to study at university.

\section{What is CU-Tep?}

CU-Tep is the acronym for Chulalongkorn University Test of English Proficiency which was modeled on the TOEFL test. CU-Tep was established, and is run by the Chulalongkorn University Language Institute. The test is aimed at Chulalongkorn University staff and students, government and private sector personnel and the general public. It is required for admission to the master and doctorate programmes. The purposes of this test are to assess the listening, reading, writing and speaking skills of those candidates who take this examination. According to the Opinion Language School (p.5), Chulalongkorn University has said these skills are "necessary for daily activities in a community where English is used as the medium of communication." It is necessary to pre-register in order to be able to take the test which is held three times during the year, in January, May and September, in the language assessment section of Chulalongkorn University Language Institute. 
The CU-Tep examination consists of three parts: listening, writing and reading. Each of these parts requires the candidates to decide which the best answer for each question is and then to blacken the space corresponding to the chosen answer on the answer sheet. For example, on the answer sheet the following is seen:
1. $\mathrm{O}$
2. $\mathrm{O}$
3. $\mathrm{O}$
4. $\mathrm{O}$

If the best answer is considered to be ' 3 ' then the circle beside this number is blackened with a pencil.

The listening section takes thirty minutes for thirty questions and generally consists of any of the following: a monologue, a public announcement, a news report, an interview, a short talk, a short dialogue or a long dialogue. An example of a public announcement and a question (Opinion, 7) given in an exam for Part 1 is:

"Sorry for interrupting the music but an urgent traffic flash. It's static on Finsbury, take any available route, and I mean anything. It's not going to get moving for at least the next hour or so, so avoid the area ..."

Q.1. What should you not do after listening to this announcement?
a. Go to a movie
b. Drive to Finsbury
c. Listen to the music programme
d. Hurry to pass the next car

The parts are spoken only once as it is the objective of the test to measure the ability of the candidate to understand English spoken at a normal rate by a native or near native speaker.

The writing test also takes thirty minutes for thirty questions and generally tests vocabulary and grammar. The objective of this test is to measure the candidate's knowledge of vocabulary, grammar and structure and this is done 
through error identification and sentence completion. An example of a writing test question which requires the candidates to identify the words or phases not acceptable in standard written English follows (Opinion, 17):

The unit's computer is linked to more than (1) 100 airlines around (2) the world, enable (3) checks to be made in seconds (4).

The reading section of the test takes seventy minutes and consists of sixty questions in five parts, and generally includes reading passages of varying lengths (short and long texts) with comprehension questions and cloze questions. The objective of this test is to measure the candidate's ability to extract literal and interpretative meanings from passages which come from a variety of sources such as newspapers, travel brochures, leaflets, magazines and excerpts from short stories and novels. The reading test therefore includes a variety of writing styles. An example of portion of a reading passage (Opinion, 14) with blanks to fill in follows:

"Small talk is a big thing," Dr Harren Hoffman says in Toastmaster magazine.

"Think of ____ as the front door to another person's public parlour and the back door to their private kitchen, where intimacy is 2 It's the appetizer before the main course, the 3 test of your ability to be invited into another's life."
1. a. it
b. that
c. this
d. such
2. a. divided
b. splitted
c. participated
d. shared
3. a. opening
b. prime
c. original
d. initial

The total time allowed for the test is 160 minutes (2 hours and 10 minutes).

CU-Tep is marked out of 120 points and the candidates are given their equivalent TOEFL score. A candidate who scores between 85 to $100 \%$ is considered a 
very good user; between 75 to $84 \%$ a competent user; 65 to $74 \%$ a moderate user; 55 to $64 \%$ a marginal user; and below $54 \%$ an extremely limited user.

\section{Gathering the Information}

This survey was carried out only at the Education section at Chulalongkorn University, and therefore does not include any students from other sections of the university, such as Architecture, Arts, Science and Technology, or Engineering etc. Consequently, the survey gives only the opinions and experiences of those students enrolled in the Education Department and not the opinions and experiences of students from other sections of Chulalongkorn University.

Sixteen students were selected to take part in this survey. The students were selected randomly, by being approached and asking them if they would answer some questions about the CU-Tep exam. To qualify to take part in this survey, each student was initially asked the same two questions: "Are you a student at Chulalongkorn University?" “Did you sit the CU-Tep examination?" Upon answering in the affirmative to both of these two questions, the student was then given the questionnaire (see Appendix A) to answer. The questionnaire had been piloted by giving these same questions to some students in the M (TEIL) class of testing and evaluation at Shinawatra University.

The questionnaire consisted of twenty-two questions. Of these, nine questions required a yes/no/not sure answer. Six questions were multiple-choice and required the students to circle the appropriate answer or answers. Seven questions required the students to give their opinion. At the beginning of the questionnaire students were able to give personal details such as name and age, and then say what they 
were studying and where they were from. At the end of the questionnaire, students were given the opportunity to write any comments if they so wished. The questions required the students to consider two aspects of CU-Tep: how they prepared for the exam and their experiences taking the exam.

\section{Findings}

The students were aged from 18 through to 46 years of age, with three quarters of them being aged between 18 and 25, while the other four students were aged 29, 31, 37 and 46 years old. Of the sixteen students, seven were from Bangkok, five did not give their place of origin and of the remaining four students, one came from each of the following provinces: Suphanburi, Angthong, Phangnga and Chantaburi. Seven students were studying for a bachelor's degree in Education, with two being first year students, two being second year students and three being third year students. Nine students were studying for their master's degrees (Education Research or Education Management), with three being first year students and six being second year students.

All sixteen students have sat the CU-Tep examination. Varying reasons have been given for doing so. Four students said that it was necessary for admission to the master's programme, eight said that it was part of the requirement to study at Chulalongkorn University, three said that they wanted to enter Chulalongkorn University to study, three students said they wanted to improve their English skills, two said they wanted to try the exam and one said to 'test my knowledge.'

All sixteen students agreed to the question that CU-Tep was compulsory in order to be able to study at Chulalongkorn University. When asked if CU-Tep was 
compulsory in order to be able to study at other universities, two replied that it was compulsory, while four said no, seven were not sure and three did not give an answer.

Twelve of the sixteen students said they have friends who have sat the CUTep exam but are not attending Chulalongkorn University, while four students said they do not have friends who have sat the exam and who are not attending the university.

Nine of the sixteen students said they prepared for the exam, while seven said they did not prepare at all. Only one student, who did not prepare, gave a reason and said this was because she did not have the time to do so. The other six students who did not prepare did not provide any reasons.

Various ways have been given as to how those students who prepared, did so: by doing lots of old exams, by studying grammar and vocabulary, by studying reading and some tests, by studying grammar and some tests, by practicing English skills and by just practicing. Several students indicated that they did a combination of things to prepare. When asked to be more explicit, six students said that their preparation involved practice exams, two said their preparation involved practicing writing, three said that their preparation involved practicing speaking, seven students said their preparation involved practicing listening, eight students said their preparation involved practicing grammar, six students said their preparation involved learning vocabulary and four students practiced reading.

When asked how they knew about the preparation for the CU-Tep exam, eight students said that friends had told them, four said they had seen an 
advertisement about preparing for the exam, one student was advised by school, one was advised by the university and one student was told by family.

When asked where they did the preparation for the CU-Tep exam, two students said they attended a private language school, one student studied at school, while only one student attended Chula language centre. However, three students mentioned that they studied with friends at home, six said they worked by themselves at home, and one said he was also helped by a family member at home.

When asked when the students did their preparation, seven said they prepared just before the exam, two students said they started preparing several months before and two said they prepared a week before the exam. Nobody replied that they did some preparation every night when they did their homework.

Of the sixteen students asked if the preparation helped, all of the nine who had prepared replied that it did help. These nine students, who prepared for the exam, gave varied replies as to how the preparation had helped them. Each student had something different to say about how the preparation had helped, such as: it helped to reduce excitement in the room, it helped me to understand, I learnt new vocabulary, it helped me to know vocabulary and grammar, I have self confidence, I got more points, it helped to practice organizing my thoughts, the preparation helped me to know the exam, and learn skills. When asked to give their opinion about the preparation, one student said "I could have done this on my own," another student said it did not make any difference, while the other seven said the preparation was useful. All of these nine students thought they got a better mark because they had prepared. 
Out of the sixteen students asked if they would tell their friends to prepare for CU-Tep, ten students replied they would, while four were not sure about telling their friends to prepare and two students did not give an answer to this question.

All students were asked what advice they would give to their friends about preparing for CU-Tep. Four students did not give an answer to this question, but the other twelve had these things to say:

"Preparation helps to improve your English and you can get good points."

"take more grammar."

"do more practice."

“always practice your English skills."

"practice listening."

"practice listening, grammar and reading."

"practice listening and reading."

"practice grammar and listening especially."

"you know how CU-Tep will be like."

“just pay attention!”

All of the students were asked to say what they thought of the CU-Tep exam. Thirteen students thought it was harder than they thought it would be, two said they should have done more preparation for this exam, one student said it was what she thought it would be, while one student commented that it was easier than he thought it would be.

The students were also given two opportunities to write their thoughts about the CU-Tep exam. The first question asked what they had thought when they first 
saw the exam, and the second question asked what they had felt after they finished the exam and had talked to their friends about it. All sixteen students had something to say about what they thought and how they felt about this exam. Their comments for both questions were similar and included such thoughts as:

"it's very difficult"

"not enough time for the listening part"

"ok because I prepared myself before"

"has lots of parts"

"there were too many questions"

"it's a good test but has a short time to do it"

"I did my best"

"it's so much harder than I thought it would be"

"it's very hard and I don't think I can pass it"

"not so exciting"

"I can't apply to study at CU"

"so hard"

"we think it's too hard"

"it's too hard for Thai students"

"I feel happy"

"I felt bad"

"I'm sad"

"it's a funny time"

"it's ok" 
"you must prepare"

"the reading part is about science and oh! ... very, very difficult"

When asked if they were happy with their score, eight students said they were, five said they were not happy, while three said they were not sure. The students were then asked to comment further, and here was what they had to say:

"I passed the requirements for the master degree."

“OK because I did not have much time to prepare."

“OK, and my family's happy with my score."

"I pass."

"I wanted 500 but can't get it."

"More than I think and helped me to apply for master degree."

“I just pass but not good score."

"I think if I prepare for the exam I shall get a better score."

"I can apply to study at Chulalongkorn University."

"My score is low."

“Because I did not prepare my English skills, my score is not good enough."

“I think if I prepared more I will get a better score."

None of the sixteen students made any additional comments at the end of the survey where they were given the option for doing so.

\section{Conclusion}

Three things have stood out in relation to this research topic. Two of these things relate to the findings and are the lack of preparation for what is considered to be an 
important examination and the fact that all students, including those who did prepare, have found the exam to be difficult. The third thing which has stood out from reading the various relevant articles is the relatively poor scores received by Thai students.

As mentioned earlier, Dr Prapphal admitted her shock upon learning the facts about the relatively poor scores received by Thai students when interviewed by The Nation (2002). Dr Prapphal's shock was also being echoed by native English language teachers, who have shown no surprise to this news, on the ajarnforum.net. However, when one considers from the findings that only nine out of sixteen students (just over half of those who sat the exam) prepared for the exam while the other seven did not, it is not so surprising. Nor are these results so surprising when one considers also, that only three out of the nine students who prepared for the exam (this is just one third) sought professional exam preparation through either a private language school or the Chula language centre. From the findings can be seen that only one of the three students prepared by studying at the latter. What is surprising is the lack of preparation by many of the students for what is considered by all the students to be a very important exam.

A further piece of interesting information has been revealed with regard to when the students did their preparation. Not one student admitted to preparing gradually over time by doing some extra study every evening when they did their homework. Out of the nine students who prepared, seven did so just before the exam, while the other two said a week before. Not enough, obviously. Surprising too, when 
considering how important this exam was considered to be by all the students, and how difficult the exam was likely to be was known by the students before they sat it.

These few facts in themselves are astounding when taking into consideration that all students participating in this questionnaire said how important this exam was and "how it was necessary/compulsory to take and pass the exam in order to be able to study or enter Chulalongkorn University" (unnamed students answering the questionnaire). One would think then that more preparation would be undertaken for such an important examination. Nor was it surprising then to learn also, that all the students found the exam to be difficult.

It was also interesting to note from listening to comments while the students were answering the questionnaire, as to the difference in attitude between the younger (bachelors) students and the older (masters) students who took the exam. The latter seemed to be more serious about the exam than their younger counterparts. Perhaps this was because these more mature students who are further ahead in their studies could see where their qualifications could take them in the future. They have most probably been giving some thought to where they go re employment once they have completed their masters in the next year or so and therefore have seen what is available to them when they have a good level of English. As Chalermwoot, a 25-year-old student studying for his Masters of Education said: "it (English) is important for us and Thailand in the future." All of the older students urged preparation.

A possible explanation for the younger students having a different attitude could be the carry over of habits and an attitude developed in preparing for exams 
during their secondary education, and also because they cannot yet see the purpose for them for English in their future. It was Dr Prapphal (2002) who mentioned that it was a must to set about motivating, setting goals and developing methods to improve their students' English ability and study skills if Thailand wishes to maintain a place in both Asia and the international world.

What then, are some recommendations for Thai students contemplating taking the CU-Tep examination? There are several things that Thai students can do, such as listen to and follow the advice of those who have previously sat the exam, do lots of preparation by taking practice tests, learn the vocabulary, and seek help from others, for example: teachers, language schools that offer preparation courses for CU-Tep and the Chulalongkorn University Language Institute.

\section{References}

Opinion Language School. (2547) Chulalongkorn University CU-Tep English for master's degree. Thailand: Skybooks.

Prapphal, K. (2001). English proficiency of Thai learners and directions of English teaching and learning in Thailand [Abstract] Chulalongkorn University Language Institute. Retrieved from

http:/ / www.pioneer.chula.ac.th/ pkanchan/doc/CU-TEP2002.DOC

Prapphal, K. (2002). Survey of English language ability of graduates of Thailand. (an investigation of English proficiency of Thai graduates.) [Abstract]

Chulalongkorn University: Academic Testing centre of Chulalongkorn University.

Retrieved from http:/www.pioneer.chula.ac.th/ pkanchan/doc/CU-

Tep2002.DOC 
Thread: Thailand scores $2^{\text {nd }}$ in S.E. Asia for English Proficiency. (2005, August). From www.ajarnforum,net. Retrieved from http:/ / www.bangkokpost/News/10Aug2005 news15.php

Vichitsorasatra, N. and Paisalpichitisodsai, J. (2002, August). English Proficiency: TOEFL shock score. The Nation. Retrieved from http:/ / www.asiantribune.com/news/2002/08/07/benglish-proficiencytoefl-score-shocker-b

Wiriyachitra, A. (2001). English language teaching and learning in Thailand in this decade. [Abstract]. Thai Tesol Focus. Retrieved from www.apecknowledgebank.org/resources/ downloads/English\%20Language\%20Teaching\%20Learning\%20in\%20Thaila ndpdf

www.aims.co.th/CU-Tep.html \}

www.atc.chula.ac.th \} for general information about CU-Tep

\section{APPENDIX A}

\section{Personal details}

Name:

Age:

What are you studying?

Where are you from?

Are you a $1^{\text {st }} \quad 2^{\text {nd }} \quad 3^{\text {rd }} \quad 4^{\text {th }} \quad 5^{\text {th }} \quad$ year student?

Did you take the cu-tep exam? yes no

Why did you take the cu-tep exam? 
Do you have friends who took the cu-tep exam but are not attending chulalongkorn university?
yes
no

Is cu-tep compulsory to study at chulalongkorn?

yes no

Or other universities? yes no not sure

Did you prepare for the cu-tep exam? yes no

How did you prepare for the cu-tep exam?

Where did you do the preparation?

Didn't prepare at school at Chula Language centre

At a private language school online

with friends worked by myself

Family helped me looked at other exams

What did the preparation involve?

Practice exams practice speaking

Practice listening practice grammar

Practice reading practice writing

Learning vocabulary

How did you know about this preparation?

Advised by my school my family told me

Friends told me the university told me

Saw an advertisement (online / notice-board)

When did you do the preparation?

Just before the exam every night when I did my homework 
Several months before A week before

Other ...

Did this preparation help? Yes no not sure

How did it help you?

Do you think you got a better mark because you prepared? Yes no not sure What was your opinion about the preparation?
Useful
not useful
very useful

Didn't make any difference

I could have done this on my own

Would you tell your friends to prepare for cu-tep? Yes no not sure What advice would you give them about preparing for cu-tep?

What did you think about the cu-tep exam?

It was harder than I thought it would be

It was easier than I thought it would be

It was what I thought it would be

It was not what I thought it would be

I'm glad I prepared for this exam

I should have done more preparation for this exam

When you first saw the exam what did you think?

When you had finished the exam and talked to your friends afterwards, how did you feel about the cu-tep exam?

Were you happy with your score? Yes no not sure Why/ why not?

Other comments: 
(Thank you so much for your time and your help.) 